\title{
广州市典型绿地土壤水分入渗特征
}

\author{
杜建会 ${ }^{1,2, *}$,方 政 ${ }^{1}$, 林志斌 ${ }^{3}$ \\ 1 中山大学地理科学与规划学院,广州 510275 \\ 2 广东省城市化与地理环境空间模拟重点实验室,广州 510275 \\ 3 广州海珠国家湿地科研宣传教育中心,广州 510305
}

\begin{abstract}
摘要: 绿地对于缓解城市洪涝灾害具有非常重要的作用,对其土壤人渗的定量化研究是评价城市绿地雨洪调蓄能力的关键。受 城市土壤空间异质性的影响,不同功能区绿地土壤水分人渗速率的差异较大。采用双环人渗仪对广州海珠国家湿地公园典型 乔草和灌草绿地的土壤水分人渗特征进行测定,并对其影响因素进行分析,结果表明: (1) 广州海珠国家湿地公园的绿地土壤 水分人渗性能处于中等至较高水平, 但受机械和人为压实作用, 绿地土壤容重偏大, 总孔隙率偏低, 加上外来客土影响, 土壤物 理性黏粒含量高, 且有人为侵人体混人等, 从而抑制了绿地表层土壤的水分人渗; (2) 灌草相对于乔草对绿地表层土壤水分人 渗的改善更为明显, 这主要与前者的根系分布较浅有关, 此外灌草绿地的调落物更易留存, 且其细根分解较快, 这均有助于表层 土壤有机质的及时返还, 从而促进了绿地表层土壤的水分人渗; (3)广州海珠国家湿地公园绿地土壤的水分累积人渗量随时间 变化更符合 Kostiakov 模型。未来广州市绿地的建设及管理应减少土壤压实及外来客土混人,适当增加灌草比例, 使其兼顾旅 游休闲和雨洪蓄积功能, 从而有助于海绵城市的高效建设。
\end{abstract}

关键词: 城市绿地; 土壤人渗; 双环人渗仪; 海珠国家湿地公园; 海绵城市

\section{Soil infiltration characteristics of typical green space in Guangzhou City}

DU Jianhui ${ }^{1,2, *}$, FANG Zheng ${ }^{1}$, LIN Zhibin ${ }^{3}$

1 School of Geography and Planning, Sun Yat-sen University, Guangzhou 510275, China

2 Guangdong Key Laboratory for Urbanization and Geo-simulation, Guangzhou 510275, China

3 Public Education and Research Center of Haizhu Wetland in Guangzhou, Guangzhou 510305, China

\begin{abstract}
Rapid soil water infiltration in green space plays an important role in the alleviation of flood hazard in urban areas, so its accurate measurement is very critical for the assessment of flood storage capacity in cities. However, the soil infiltration rate of green space in different functional zones varied greatly due to the high spatial heterogeneity in urban soil. In this paper, soil infiltration rate was measured using a double ring infiltrometer and its influencing factors were analyzed in Haizhu National Wetland Park, Guangzhou city. The results indicated that: (1) soil water infiltration capacity in green space of the Haizhu National Wetland Park could be classified as the middle to relatively high level. However, the soil physical clay content and bulk density in our study area were relatively higher, while soil non-capillary porosity was relatively lower in green space soil compared with the natural soil, which could be attributed to its soil source mainly transported from other places, such as pond sludge. Moreover, heavy soil compactions from both mechanical and human activities, as well as mixture of anthropogenic intrusions due to the mismanagement of urban solid waste, which all contributed to the inhibition of soil water infiltration in urban green space. (2) Plantation of shrubs and grasses could greatly improve the soil water infiltration capacity in surface soil of urban green space compared with the plantation of trees and grasses, which was due to the relatively shallow root distribution of shrubs in soils. In addition, more difficulty in
\end{abstract}

基金项目: 国家自然科学基金项目 (41101011,41801101); 中山大学实验室开放基金重点项目(201902011)

收稿日期: 2020-09-09; 网络出版日期:2021-08-04

*通讯作者 Corresponding author.E-mail: dujh1982@ hotmail.com 
cleaning the leaf and branch litter, and higher decomposition rate with finer roots were more commonly observed in urban green space with shrubs and grasses, which both contributed to the rapid feedback of litter from leaves, branches and roots, facilitated the increase of the surface soil organic content, and further enhanced the soil water infiltration capacity in urban green space. (3) With higher $R^{2}$ and lower RMSE, the variation of cumulative infiltration of soil water into the urban green space could be better simulated through the Kostiakov model. The establishment and management of urban green space should focus more on the combined plantation of trees, shrubs and grasses, especially the increase of shrub plantations, while reduce the use of soil from other places, particularly the soil with high physical clay content, and weaken the soil compaction by building the specified passage and recreation area, which will balance the functions between leisure and flood storage in urban green space, and facilitate the development of sponge city in Guangzhou.

Key Words : urban green space; soil infiltration; double ring infiltrometer; Haizhu National Wetland Park; sponge city

城市化作为人类对自然生态系统最强烈的改造方式, 深刻地影响着城市地表环境的结构与功能 ${ }^{[1-2]}$,城 市化过程中不透水面积急剧增加,显著改变了城市的自然水循环过程 ${ }^{[3-4]}$ 。此外,随着气候变化,极端降雨的

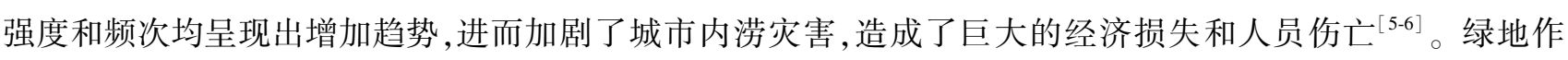
为城市中心最重要的可透水层, 其通过调蓄雨水、削减洪峰和雨污净化, 有效推动了海绵城市的高效建设, 在 减缓城市洪涝灾害等方面具有不可或缺的作用 ${ }^{[7-9]}$ 。因此, 快速的土壤人渗就成为城市绿地建设的关键 ${ }^{[10]}$ 。 近三十年来, 德国、日本、美国等发达国家均对城市绿地土壤的人渗性能提出了相关要求, 确保新建和改建的 区域地表径流量实现 “零增长”。并通过建造雨水花园和下凹型绿地等, 进一步提升城市绿地土壤的人渗和 蓄水性能, 在减缓城市雨洪灾害等方面取得了显著的成就 ${ }^{[11]}$ 。我国国务院办公厅也于 2015 年出台了《关于 推进海绵城市建设的指导意见》, 明确规定通过海绵城市建设, 确保 70\%的降雨就地消纳和利用,减少城市化 对生态环境的影响。

城市绿地作为海绵城市系统的重要载体, 其面积呈逐年增长趋势 ${ }^{[12]}$ 。但已有的研究表明,绿地并未起到 有效缓解城市内涝的作用 ${ }^{[13-14]}$ 。许多学者通过室内和野外试验, 对城市不同功能区的绿地土壤水分人渗速 率进行了测定, 分析了其影响因素, 并在此基础上采用多个人渗模型对绿地土壤的水分人渗过程进行拟合。 结果发现, 城市绿地土壤的水分人渗速率相对较小, 但不同功能区的绿地土壤来源复杂, 且植被类型多样, 其 土壤水分人渗速率的空间差异较大 ${ }^{[15-18]}$ 。首先, 城市绿地土壤多来自于杂填土, 无明显土壤结构, 土壤含砂

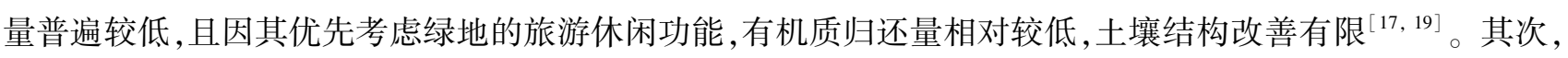
城市绿地作为市民重要的休想地,一般表现为植被覆盖度越低, 人为踩踏越多, 土壤渗透性越差 ${ }^{[19-21]}$ 。此外, 植被类型不同, 土壤人渗速率也有所差异, 乔灌草绿地的人渗性能好于乔草和灌草 ${ }^{[22]}$ 。基于多个人渗模型的 拟合表明, 其均可以很好地反映城市绿地土壤的水分人渗过程, 以 Kostiakov 模型或 Horton 模型最佳 ${ }^{[16,21-24]}$ 。 近些年来, 为了增加雨水蓄积及地表人渗, 许多城市开展下凹式绿地建设 ${ }^{[15]}$, 其在一定程度上起到了蓄渗减 洪的效果, 也能对雨水及径流污染物起到削减作用, 但随着蓄水次数的增多, 其土壤容重增加, 总孔隙度减小, 绿地的人渗性能逐渐退化 ${ }^{[25]}$ 。因此, 如何维持绿地高效且可持续的水分下渗, 就成为缓解城市内涝灾害的 关键。

随着粤港澳大湾区的建设, 不透水面积在广州市主城区不断增加, 洪涝灾害也随之加剧。海珠国家湿地 公园 (简称海珠湿地) 作为广州市主城区的两大生态屏障之一,被称为广州市的“南肾”,其良好的土壤水分人 渗性能对于缓解广州市的洪涝灾害就显得尤为重要。海珠湿地于 2012 年建成开园, 湿地一期经人工栽种园 艺观赏植被, 形成以乔草和灌草为主的绿地。但不同类型绿地的人流量、园林植物的根系分布和有机质归还 能力等均存在明显差异, 使得各功能区的绿地土壤水分人渗空间变异较大, 目前尚不清楚海珠湿地的人渗性 能如何, 无法为现有绿地管理及后续绿地的建设提供科学依据。因此, 对海珠湿地土壤水分人渗速率的定量 化研究, 就成为准确评估其雨洪调蓄能力的关键。本文采用双环人渗仪, 选择海珠湿地公园一期典型乔草和 
灌草绿地, 对其土壤水分的人渗过程进行野外试验观测, 并对其影响因素进行分析, 以期准确评估海珠湿地的 雨洪调蓄能力,并为我国海绵城市的高效建设提供建议。

\section{1 材料与方法}

\section{1 研究区概况}

海珠国家湿地公园位于广州市中心城区海珠区的东南部,包括万亩果园和海珠湖,是广州市规模最大、保 存最完整的湿地,总面积达 $1100 \mathrm{hm}^{2}$ 。海珠湿地的前身是广州市万亩果园及与之相交的 40 条河涌, 目前已完 成三期建设。其中湿地一期位于石榴岗河北岸，属园内建成时间最早、园艺观赏植被景观最为集中的区域。 考虑到城市绿地土壤的异质性较大,因此结合园区规划图,并在实地勘测的基础上,选择湿地一期的玉龙桥南 岸以及花溪两处地势平坦, 连续广泛, 群系相似的新建人工绿地开展土壤水分人渗试验。两个样地的主要植 物种具体如下: (1) 玉龙桥样地 $\left(23^{\circ} 04^{\prime} 30^{\prime \prime} \mathrm{N}, 113^{\circ} 19^{\prime} 51^{\prime \prime} \mathrm{E}\right)$, 建群种为羊蹄甲 (Bauhinia purpurea), 灌木层优势 种为灰莉 (Fagraea ceilanica), 草本主要为结缕草 (Zoysia japonica)、蓝花草 (Ruellia simplex)。(2) 花溪样地 $\left(23^{\circ} 04^{\prime} 39^{\prime \prime} \mathrm{N}, 113^{\circ} 20^{\prime} 10^{\prime \prime} \mathrm{E}\right.$ ), 建群种为羊蹄甲 (Bauhinia purpurea), 灌木层优势种为琴叶珊瑚 (Jatropha integerrima), 草本主要为结缕草 (Zoysia japonica)。

\section{2 样品采集与测定}

2018 年 11 月 11 日一-25 日,在两处新建人工绿地选择乔草和灌草典型分布区作为样地。在土壤水分人 渗试验开展之前, 首先沿树干基部按 $120^{\circ}$ 间隔分三个不同方向, 分别设置 $1 \mathrm{~m} \times 1 \mathrm{~m}$ 的样方各 1 个, 并对样方 内的调落物进行采集,共计 12 个。试验结束后, 在人渗区域附近开挖土壤剖面, 以 $10 \mathrm{~cm}$ 为间隔,用环刀法逐 层采集 0-40 cm 的原状土,并以土钻法采集对应层次的根系样品,每层各设置 3 个平行重复。所有样品带回 实验室后,土壤样品使用激光粒度分析仪 (Mastersize 2000,马尔文公司,英国)测定其粒径,并依据卡庆斯基土 壤质地标准将绿地土壤划分为重壤土; 参照《森林土壤分析方法》 ${ }^{[26]}$ 测定土壤容重、毛管持水量和最大持水 量, 并依据相关公式计算得到绿地土壤的总孔隙度、毛管孔隙度和非毛管孔隙度等 (表 1 )。调落物样品采用 手工清除其表面的土粒和混人的杂物, 根系样品采用水洗法清洗干净, 均放人烘箱中在 $70^{\circ} \mathrm{C}$ 下烘干至恒重, 并称取其干质量。

表 1 不同植被类型绿地的土壤物理性质

Table 1 Soil physical properties in different types of green spaces

\begin{tabular}{|c|c|c|c|c|c|c|}
\hline $\begin{array}{l}\text { 绿地 } \\
\text { Green space }\end{array}$ & $\begin{array}{l}\text { 土层 } \\
\text { Soil layer/cm }\end{array}$ & $\begin{array}{c}\text { 容重 } \\
\text { Bulk density/ } \\
\left(\mathrm{g} / \mathrm{cm}^{3}\right)\end{array}$ & $\begin{array}{c}\text { 总孔隙度 } \\
\text { Total } \\
\text { porosity } / \%\end{array}$ & $\begin{array}{c}\text { 毛管孔隙度 } \\
\text { Capillary } \\
\text { porosity/\% }\end{array}$ & $\begin{array}{c}\text { 非毛管孔隙度 } \\
\text { Non-capillary } \\
\text { porosity/\% }\end{array}$ & $\begin{array}{c}\text { 物理性黏粒 } \\
\text { Physical clay } \\
(<0.01 \mathrm{~mm}) / \%\end{array}$ \\
\hline 玉龙桥乔草( YLQC) & $0-10$ & 1.41 & 46.82 & 45.65 & 1.17 & 49.64 \\
\hline \multirow[t]{3}{*}{ Trees and grasses } & $10-20$ & 1.45 & 45.41 & 45.19 & 0.23 & 47.90 \\
\hline & $20-30$ & 1.44 & 45.54 & 45.34 & 0.20 & 47.69 \\
\hline & $30-40$ & 1.44 & 45.56 & 45.20 & 0.35 & 47.90 \\
\hline 玉龙桥灌草( YLGC) & $0-10$ & 1.36 & 48.54 & 48.14 & 0.40 & 51.01 \\
\hline \multirow[t]{3}{*}{ Shrubs and grasses } & $10-20$ & 1.29 & 51.20 & 48.34 & 2.87 & 50.92 \\
\hline & $20-30$ & 1.33 & 49.83 & 48.52 & 1.30 & 49.47 \\
\hline & $30-40$ & 1.31 & 50.65 & 48.06 & 2.59 & 48.82 \\
\hline 花溪乔草(HXQC) & $0-10$ & 1.30 & 51.00 & 44.08 & 6.92 & 48.97 \\
\hline \multirow[t]{3}{*}{ Trees and grasses } & $10-20$ & 1.37 & 48.46 & 44.42 & 4.04 & 51.01 \\
\hline & $20-30$ & 1.44 & 45.76 & 44.03 & 1.72 & 48.68 \\
\hline & $30-40$ & 1.42 & 46.44 & 43.81 & 2.63 & 50.59 \\
\hline 花溪灌草( HXGC) & $0-10$ & 1.19 & 55.19 & 46.88 & 8.31 & 52.06 \\
\hline \multirow[t]{3}{*}{ Shrubs and grasses } & $10-20$ & 1.38 & 47.80 & 42.28 & 5.53 & 52.58 \\
\hline & $20-30$ & 1.20 & 54.64 & 45.70 & 8.95 & 53.31 \\
\hline & $30-40$ & 1.43 & 46.02 & 46.00 & 0.02 & 52.19 \\
\hline
\end{tabular}




\section{3 绿地土壤水分人渗测定}

在两处绿地各选择乔草和灌草样地 1 块, 采用双环人渗仪 (QT-IN12-W, 渠道科学仪器有限公司, 中国) 对 其土壤水分的人渗特征进行测定。该仪器内环直径 $30 \mathrm{~cm}$ 、外环直径 $60 \mathrm{~cm}$, 可最大程度减少城市绿地土壤空 间异质性的影响。试验前 $48 \mathrm{~h}$ 内无降水或人工灌溉出现, 其人渗过程受土壤前期水分影响不大。在尽量减 少表土扰动的情况下, 将待测样地的草本植物修剪至近似地表平整。双环插人土壤 $10 \mathrm{~cm}$,使用 $10 \mathrm{~L}$ 的马氏 管向内环供水, 人工加水至外环的泡沫板上, 以防止水流冲刷土壤表层产生结皮。试验开始后水头稳定地控 制在 $8 \mathrm{~cm}$, 记录马氏管每 $500 \mathrm{~mL}$ 刻度下降的时间, 至 $70 \mathrm{~min}$ 后停止试验。人渗速率转化为水温为 $10{ }^{\circ} \mathrm{C}$ 的 土壤人渗速率。

土壤水分人渗参数的计算公式为:

$$
I_{T}=\frac{Q \times 10}{S_{2} \times(0.7+0.03 T)}
$$

式中, $I_{T}$ 为一定温度下的土壤水分累积人渗量 $(\mathrm{mm}) ; Q$ 为试验开始后马氏管的累积供水量 $\left(\mathrm{cm}^{3}\right) ; 10$ 为 $\mathrm{cm}$ 与 $\mathrm{mm}$ 间的转化系数; $S_{2}$ 为双环内环的横截面积 $\left(\mathrm{cm}^{2}\right) ; T$ 为某时段的平均水温 $\left({ }^{\circ} \mathrm{C}\right)$ 。

$$
V_{T}=\frac{\left(Q_{t}-Q_{t-1}\right) \times 10}{S_{2} \times \Delta t(0.7+0.03 T)}
$$

式中, $V_{T}$ 为一定温度下 $t$ 时刻的土壤垂直人渗速率 $(\mathrm{mm} / \mathrm{min}) ; Q_{t}$ 为 $t$ 时刻的马氏管的累积供水量 $\left(\mathrm{cm}^{3}\right) ; Q_{t-1}$ 为 $t-1$ 时刻马氏管的累积供水量 $\left(\mathrm{cm}^{3}\right) ; S_{2}$ 为内环面积 $\left(\mathrm{cm}^{3}\right) ; 10$ 为 $\mathrm{cm}$ 与 $\mathrm{mm}$ 间的转化系数; $\Delta t$ 为观测间隔 时间差 $(\min ) ; T$ 为某时段的平均水温 $\left({ }^{\circ} \mathrm{C}\right)$ 。

\section{4 绿地土壤入渗过程的拟合}

参照方政等 ${ }^{[9]}$ 的研究结果, 分别选用物理意义明确的 Philip 模型、半经验的 Horton 模型和经验性的 Kostiakov 模型对野外人渗量的实测数据进行拟合。相关数据分析在 SPSS 13.0 进行, 作图采用 Origin 9.0 进行。

Philip 模型：

$$
I(t)=S t^{\frac{1}{2}}+A t
$$

式中, $I(t)$ 为累积人渗量 $(\mathrm{mm}) ; S$ 为吸渗率 $\left(\mathrm{mm} / \mathrm{min}^{1 / 2}\right) ; A$ 是与稳定人渗率 $(\mathrm{mm} / \mathrm{min})$ 有关的参数; $t$ 为时间 $(\min )$ 。

Horton 模型:

$$
I(t)=i_{f} t+\left(i_{i}-i_{f}\right)\left(1-e^{-c t}\right) / c
$$

式中, $i_{i}$ 为初始人渗率 $(\mathrm{mm} / \mathrm{min}) ; i_{f}$ 为稳定人渗率 $(\mathrm{mm} / \mathrm{min}) ; c$ 为常数; $t$ 为时间 $(\mathrm{min})$ 。

Kostiakov 模型:

$$
I(t)=a t^{n}
$$

式中, $a$ 和 $n$ 为经验系数; $t$ 为时间 ( $\min )$ 。

\section{2 结果与分析}

\section{1 不同植被类型对城市绿地土壤水分人渗速率的影响}

城市绿地土壤的人渗速率随时间变化的趋势总体较为一致,均表现为前期急剧下降、中期波动下降和后 期逐渐稳定 3 个阶段。从不同样地来看, 花溪样地的土壤水分人渗速率下降较快, 其中乔草绿地初始人渗速 率为 $3.26 \mathrm{~mm} / \mathrm{min}$, 稳定人渗速率为 $0.94 \mathrm{~mm} / \mathrm{min}$, 而灌草绿地的初始人渗速率为 $3.93 \mathrm{~mm} / \mathrm{min}$, 稳定人渗速 率为 $1.08 \mathrm{~mm} / \mathrm{min}$ (图 1); 玉龙桥样地的土壤水分人渗速率下降则较为平缓, 其中乔草绿地的初始人渗速率 为 $4.14 \mathrm{~mm} / \mathrm{min}$, 稳定人渗速率为 $1.37 \mathrm{~mm} / \mathrm{min}$, 而灌草绿地的初始人渗速率为 $5.25 \mathrm{~mm} / \mathrm{min}$, 稳定人渗速率 为 $1.80 \mathrm{~mm} / \mathrm{min}$ (图 1)。同一植被类型均表现为花溪样地的土壤水分初始人渗速率 (乔草: $P=0.012$; 灌草: 
$P=0.002$ ) 和稳定人渗速率 (乔草: $P=0.000$; 灌草: $P=0.000$ ) 显著小于玉龙桥样地。从不同植被类型来看, 同 一样地均表现为乔草绿地的初始人渗速率 (花溪: $P=0.239$; 玉龙桥: $P=0.311$ ) 和稳定人渗速率 (花溪: $P=$ 0.000 ; 玉龙桥: $P=0.000)$ 小于灌草, 其中乔草和灌草的稳定人渗速率差异达到了显著水平。

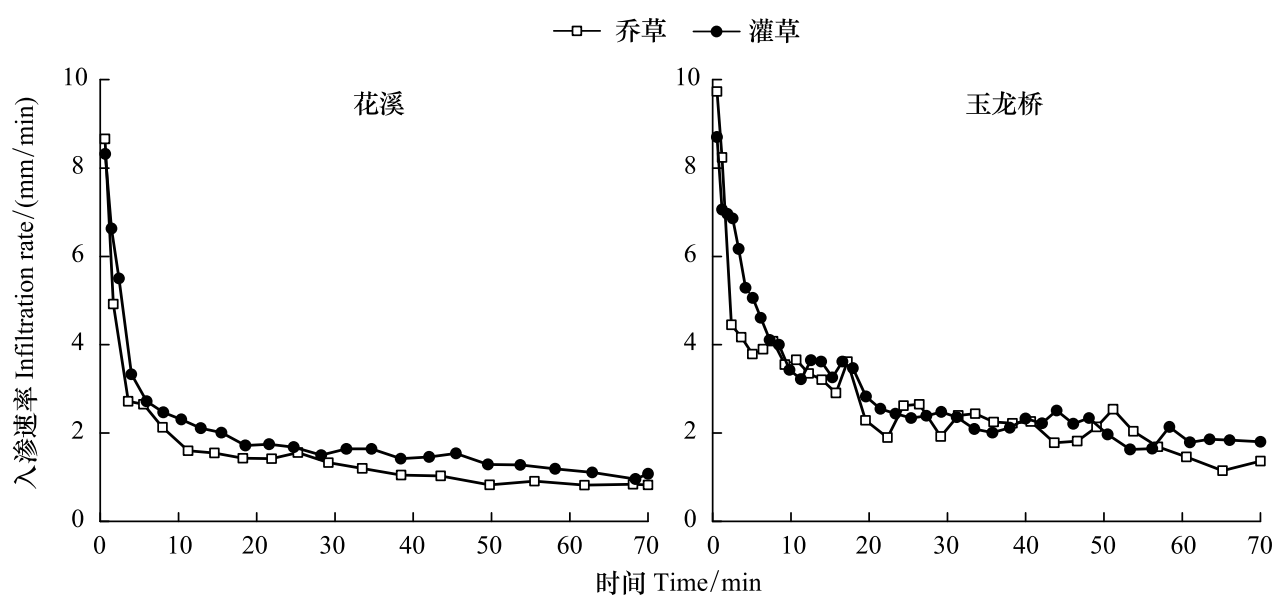

图 1 不同植被类型城市绿地土壤的水分入渗速率变化特征

Fig.1 Soil water infiltration characteristics in different types of urban green spaces

2.2 不同植被类型对绿地土壤水分累积人渗量的影响

不同样地土壤水分的累积人渗量随时间的变化趋势总体一致,均随着时间的延长渐趋平缓,但其单位时 间的累积人渗量有所差异。花溪样地的乔草绿地和灌草绿地土壤 $70 \mathrm{~min}$ 内的累积人渗量为分别为 $97 \mathrm{~mm}$ 和 $123 \mathrm{~mm}$, 而玉龙桥样地的乔草绿地和灌草绿地土壤 $70 \mathrm{~min}$ 内的累积人渗量分别为 $155 \mathrm{~mm}$ 和 $190 \mathrm{~mm}$ (图 2), 同一植被类型均表现为花溪样地单位时间的累积人渗量显著小于玉龙桥样地 $(P=0.000)$ 。随着人渗时间的 延长, 不同植被类型绿地的土壤累积人渗量差异逐渐增大, 且均表现为灌草绿地累积人渗量显著大于乔草绿 地 $(P=0.000)$ 。

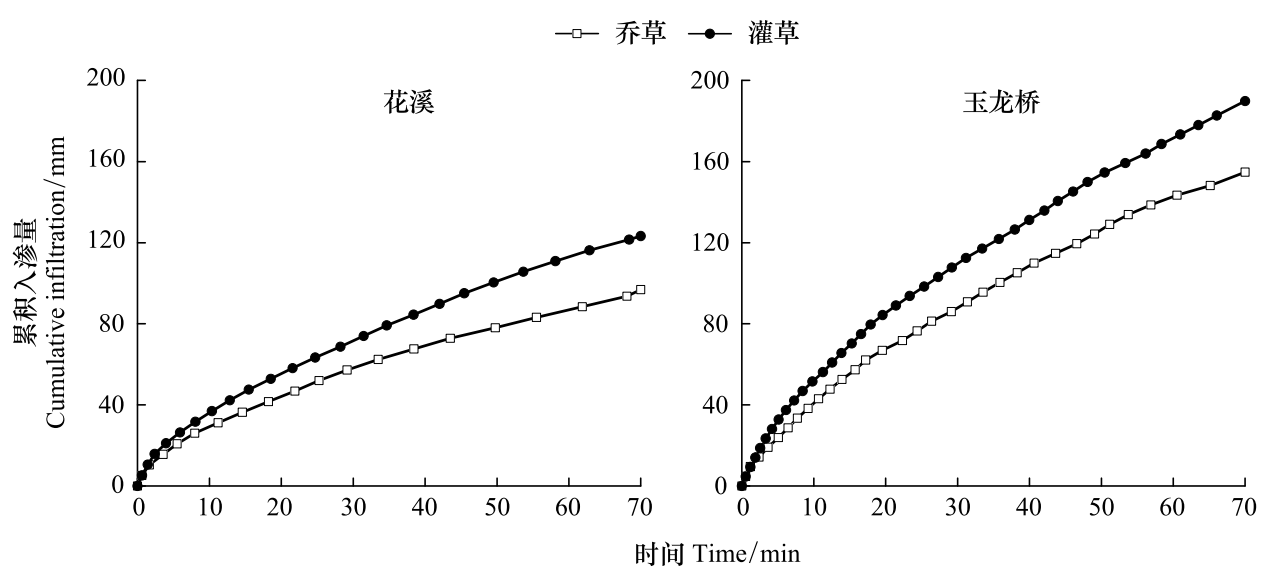

图 2 不同植被类型绿地土壤的累积入渗量变化特征

Fig.2 Cumulative infiltration of soil water in different types of green spaces

2.3 绿地土壤水分人渗过程的拟合

为进一步研究不同植被类型对绿地土壤水分人渗过程的影响,采用 3 个经典人渗模型对不同植被类型影 响下的土壤人渗量拟合发现, 与同一样地的乔草绿地相比, Philip 模型中的灌草绿地 $S$ 值 (土壤的吸渗率) 和 
$A$ 值( 与稳定人渗率有关的参数) 均相对偏大, 表明灌草绿地的土壤水分人渗性能更佳。Horton 模型和 Kostiakov 模型所对应的 $i_{i}$ 值, $i_{f}$ 值和 $a$ 值也均表现为同一样地下, 灌草绿地的土壤水分人渗能力大于乔草型 绿地,三个模型均很好地反映了不同植被类型绿地土壤水分的人渗差异。其次, Philip、Horton 和 Kostiakov 模 型的 $R^{2}$ 均值分别为 $0.998,0.998$ 和 0.999 , RMSE 均值分别为 $1.682 、 1.434 、 0.959 \mathrm{~mm}$ (表 2)。综上所知,三个模 型的相关参数均能很好地反映不同植被类型绿地的土壤水分人渗差异, 但与 Philip 、 Horton 模型相比, Kostiakov 模型拟合的 $R^{2}$ 最高, RMSE 最低,且其相对于其他两个模型能够更好地拟合研究区城市绿地的土壤 水分人渗过程。

本研究的野外绿地土壤人渗试验持续至 70 min 后结束, 基于 Kostiakov 模型预测可知,玉龙桥乔草和灌草 绿地的累积人渗量分别为 $158 \mathrm{~mm}$ 和 $191 \mathrm{~mm}$ (野外观测值分别为 $155 \mathrm{~mm}$ 和 $190 \mathrm{~mm}$ ), 花溪乔草和灌草绿地 的累积人渗量分别为 $96 \mathrm{~mm}$ 和 $124 \mathrm{~mm}$ (野外观测值分别为 $97 \mathrm{~mm}$ 和 $123 \mathrm{~mm}$ ), 与野外观测所得的累积人渗 量差异较小。从不同植被类型绿地来看, 参数 $a$ 均表现为灌草绿地大于乔草绿地, 这很好地反映了初始人渗 阶段,灌草绿地的人渗速率显著大于乔草绿地。随着入渗过程的进行, 灌草绿地的累积人渗量 $I(t)$ 也在每一 时段均大于乔草绿地, 且二者的差异随着人渗时间的延长而逐渐增大。此外, Kostiakov 模型为幕函数, 其常 数项 $0<n<1$, 该模型可以很好地反映土壤累积人渗量随着时间延长逐渐趋于饱和的过程, 因而可被应用于评 价城市绿地土壤水分的人渗性能。

表 2 Philip、Horton、Kostiakov 模型拟合参数结果

Table 2 Model parameters of Philip, Horton and Kostiakov for simulation of soil water infiltration

\begin{tabular}{|c|c|c|c|c|c|c|c|c|c|c|c|c|c|}
\hline \multirow{2}{*}{$\begin{array}{c}\text { 绿地类型 } \\
\text { Green } \\
\text { space } \\
\text { type }\end{array}$} & \multicolumn{4}{|c|}{$\begin{array}{l}\text { Philip 模型 } \\
\text { Philip model }\end{array}$} & \multicolumn{5}{|c|}{$\begin{array}{l}\text { Horton 模型 } \\
\text { Horton model }\end{array}$} & \multicolumn{4}{|c|}{$\begin{array}{l}\text { Kostiakov 模型 } \\
\text { Kostiakov model }\end{array}$} \\
\hline & $\begin{array}{c}S / \\
\left(\mathrm{mm} / \min ^{1 / 2}\right) \\
\end{array}$ & $\begin{array}{c}A / \\
(\mathrm{mm} / \mathrm{min})\end{array}$ & $R^{2}$ & $\begin{array}{c}\text { RMSE/ } \\
\mathrm{mm}\end{array}$ & $\begin{array}{c}i_{i}{ }^{\prime} \\
(\mathrm{mm} / \mathrm{min}) \\
\end{array}$ & $\begin{array}{c}\text { iff } \\
(\mathrm{mm} / \mathrm{min})\end{array}$ & $c$ & $R^{2}$ & $\begin{array}{c}\text { RMSE/ } \\
\mathrm{mm}\end{array}$ & $a$ & $n$ & $R^{2}$ & $\begin{array}{c}\text { RMSE/ } \\
\mathrm{mm}\end{array}$ \\
\hline 玉龙桥草地 & 9.751 & 1.126 & 0.998 & 2.171 & 5.264 & 1.637 & 0.083 & 0.999 & 1.468 & 8.473 & 0.689 & 0.999 & 1.223 \\
\hline 玉龙桥灌草 & 13.069 & 1.197 & 0.998 & 2.642 & 7.246 & 1.987 & 0.100 & 1.000 & 1.083 & 11.436 & 0.662 & 0.999 & 1.365 \\
\hline 花溪乔草 & 8.150 & 0.409 & 0.999 & 0.925 & 4.642 & 0.982 & 0.129 & 0.997 & 1.510 & 7.305 & 0.607 & 1.000 & 0.594 \\
\hline 花溪灌草 & 9.473 & 0.657 & 0.999 & 0.988 & 5.967 & 1.355 & 0.147 & 0.998 & 1.673 & 8.371 & 0.634 & 1.000 & 0.655 \\
\hline
\end{tabular}

$S$ : 吸渗率 Soil sorptivety ; $A$ : 与稳定人渗速率有关的参数 Parameter related to the stable infiltration rate;RMSE: 均方根误差 Root mean square error; $i_{t}$ : 初始人渗速率 Initial infiltration rate; $i_{f}$ : 稳定人渗速率 Stable infiltration rate; $c$ : 常数 Constant; $a$ 和 $n$ 均为经验系数 both $a$ and $\mathrm{n}$ are empirical coefficients.

\section{3 讨论}

\section{1 土壤物理性质对绿地土壤水分人渗的影响}

本文研究表明,海珠湿地的土壤稳定人渗速率为 $0.94-1.80 \mathrm{~mm} / \mathrm{min}\left(1.57 \times 10^{-5}-3.00 \times 10^{-5} \mathrm{~m} / \mathrm{s}\right)$, 略大

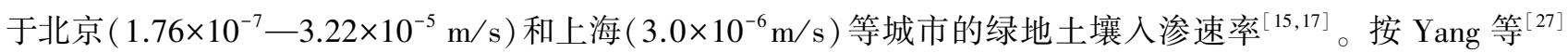
提出的城市绿地人渗标准, 其土壤水分稳定人渗速率属于中等至较快水平, 这主要与海珠湿地的建成时间较 短有关。从本文的采样来看, 海珠湿地表层 0-10 $\mathrm{cm}$ 的土壤容重在 $1.19-1.41 \mathrm{~g} / \mathrm{cm}^{3}$, 基本符合绿化种植土 壤容重小于 $1.35 \mathrm{~g} / \mathrm{cm}^{3}$ 的技术规范, 且远小于其他城市的绿地表层土壤容重 ${ }^{[13,25]}$, 可能也在一定程度上有助 于其表层土壤的水分下渗。

但与自然土壤相比, 海珠湿地的土壤水分人渗速率仍然偏低, 这主要与城市土壤普遍存在压实有关。压 实导致土壤颗粒遭受挤压,使得非毛管孔隙向毛管孔隙转变,堵塞了水分通过大孔隙向深层土壤快速运移的 通道,进而影响到绿地土壤的水分人渗 ${ }^{[13,28]}$ 。海珠湿地在建设过程中, 大量地使用重型机械搬运客土和平整 地表,造成了严重的机械压实。其次, 海珠湿地在建成后,其作为广州市公众休闲娱乐的主要场所之一, 人流 量较为集中, 频繁的人为踩踏导致绿地土壤容重增加, 且远高于自然土壤的平均容重 ${ }^{[19,29-30]}$ 。绿地土壤的容 重越大, 其非毛管孔隙度越低, 因而渗透性也随之越差 ${ }^{[15-16]}$ 。Wang 等 $^{[31]}$ 对长春市城市绿地土壤的人渗研究 证实, 城市不同类型绿地的土壤水分稳定人渗速率差异较大, 乔灌草组合的绿地土壤人渗速率最高, 而乔木下 
面只有裸地的区域土壤人渗速率较低,这一差异主要与后者所在的区域人流量较大, 对地表不断的踩踏压实 有关。Alizadehtazi 等 ${ }^{[32]}$ 对不同透水地表的人渗速率研究也表明,四周隔离的树池其人渗速率之间没有差异, 而没有隔离的树池则差异较大,这一差异主要与未受隔离的树池土壤受到行人或机动车辆压实的频率高低有 关。本研究也发现, 同一样地均表现为乔草绿地土壤的累积人渗量显著小于灌草绿地,这可能与不同植被类 型绿地对游客的可达性及吸引力差异有关 ${ }^{[22,33]}$ 。乔木巨大的冠幅有助于户外遮阴等, 可吸引游客的驻足休 憩, 因而加剧了乔草绿地的土壤压实, 而灌木遭受人为踩踏较少。频繁的踩踏导致乔草绿地土壤容重偏高、而 总孔隙度与非毛管孔隙度偏低, 这也与本文的室内测定结果比较一致。因此, 应大力种植灌木或乔灌木并植, 促进城市绿地的土壤水分下渗 ${ }^{[19]}$ 。未来仍需加强不同压实强度和频率下, 各功能绿地土壤的水分人渗速率 研究, 确定最佳的人为干扰程度, 使得城市绿地在保持其旅游休闲功能的同时, 也能兼顾雨洪蓄积的角色。

其次, 海珠湿地土壤的人渗速率偏低也与其客土的来源有关 ${ }^{[17-18,23]}$ 。客土来源不同,其土壤质地也有所 差异,进而影响到绿地的土壤水分下渗 ${ }^{[16]}$ 。海珠湿地的前身是万亩果园, 果农为了追求挂果率, 每年会采用 沟渠底泥上基的方法来提升土壤肥力, 在一定程度上使得海珠湿地的土壤物理性黏粒含量偏高 ${ }^{[34]}$ 。室内分 析表明,海珠湿地土壤的物理性黏粒含量在 48.28\%-52.53\%之间。与自然土壤相比,其土粒比表面积更大, 大孔隙含量更低 ${ }^{[28]}$, 因而对下渗水分的吸持能力更强, 单位水势梯度下的水分传导速率变小, 湿润锋下移减 缓。在下渗的过程中,土壤表面黏粒的散发和膨胀也会促进表土结皮的发育,使得土壤中未及时排出的空气 被包被,进而抑制水分的持续下渗 ${ }^{[23]}$ 。此外, 土壤黏粒也会随着水分下渗堵塞在大孔隙中,使得毛管空隙增 多而大孔隙进一步减少 ${ }^{[16,35]}$ 。大孔隙在土壤孔隙中的占比虽小,但其对于优先流的形成及土壤饱和导水率 的变化起着主导作用 ${ }^{[19]}$ 。因此, 土壤物理性黏粒偏高会减缓水分在土壤有效通道中的运移, 从而降低绿地土 壤的水分人渗速率 ${ }^{[19]}$ 。李卓等 ${ }^{[35]}$ 通过土柱模拟入渗试验也发现, 土壤容重相近时, 其 $90 \mathrm{~min}$ 累积人渗量、稳 定人渗速率与物理性黏粒含量分别呈指数负相关、幂函数负相关关系。这与本研究结果也比较一致, 玉龙桥 绿地的土壤物理性黏粒含量小于花溪绿地, 在同一植被类型下,70 min 内的土壤累积人渗量和稳定人渗速率 均表现为玉龙桥绿地大于花溪绿地。但土壤粒径过大, 绿地的保水保肥能力又会减弱, 同时也会影响其对污 染物的净化功能。未来需要根据不同功能绿地的建设需求,选用合适的土壤改良材料,维持城市绿地高效且 可持续的人渗性能 ${ }^{[24]}$ 。

最后,万亩果园北侧毗邻龙潭村,该村作为广州市典型的城中村,其城市废弃物早期因垃圾分类不当或管 理不善而混人土壤,使得在此基础上建成的海珠湿地土壤结构发生改变,进而影响到其土壤的水分下渗 ${ }^{[15]}$ 。 本研究野外土壤样品采集过程中发现, 海珠湿地土壤中混人了混凝土块、砖块、塑料和布条等人为侵人体。方 政等 ${ }^{[9]}$ 研究表明, 人为侵人体的出现会降低土壤总孔隙度, 减少水分下渗的过水断面积, 增加水分人渗通道 的弯曲程度, 进而抑制绿地的土壤水分下渗, 以混凝土块的抑制作用最为明显。人为侵人体的类型、含量及分 布的土壤层位不同, 其对城市绿地土壤水分人渗过程的影响也有所差异, 未来仍需加强不同人为侵人体影响 下的绿地土壤水分人渗过程研究。

\section{2 植被类型对绿地土壤水分人渗的影响}

植物对绿地土壤水分人渗的影响,主要是通过根系穿插、分割和扩张等机械作用使得土壤产生孔隙和裂 隙, 增加土壤大孔隙的数量和连通程度, 进而提高绿地土壤的水分人渗性能 ${ }^{[18,36]}$ 。根系在土壤中的分布特征 不同, 其对绿地土壤水分人渗的影响也有差异。本文研究发现, 同一样地灌草绿地的累积人渗量均显著大于 乔草绿地, 这与杨倩等 ${ }^{[33]}$ 的研究结果比较一致。数量多、密度大的 $0.5-2 \mathrm{~mm}$ 径级的根系是改善土壤入渗性 能的关键, 其通过增加优先流路径长度, 进而促进绿地土壤的水分人渗 ${ }^{[1,37-38]}$ 。对研究区绿地植物的根系调 查发现, 灌草型绿地植物的根系主要集中分布于 0-20 cm 土层, 该土层的平均根密度为 $2.19 \mathrm{mg} / \mathrm{cm}^{3}$, 且径级 小, 密度大, 增加了非毛管空隙的分布, 减弱了人渗水流的阻力, 使得单位水势梯度下的土壤水力传导度增 $大^{[23]}$, 有利于绿地表层土壤水分下渗。而乔草型绿地植物的根系主要分布于 $20 \mathrm{~cm} \mathrm{以下,} 0-20 \mathrm{~cm}$ 土层的根 密度仅为 $0.62 \mathrm{mg} / \mathrm{cm}^{3}$, 且其根系粗大, 密度小, 降低了乔木根系与上层草本根系的连通程度, 因而对绿地表层 
土壤水分人渗性能的改善有限。Rahman 等 ${ }^{[6]}$ 对刺槐 (Robinia pseudoacacia) 和欧洲椴 (Tilia cordata) 冠层下的 土壤人渗速率研究也表明,前者的土壤入渗速率显著大于后者,主要在于前者的细根生物量密集分布于土壤 表层,从而穿插形成非常多的小孔隙,有助于土壤水分下渗,而后者根系分布则相对较深, 不利于林冠下土壤 表层水分下渗。但随着土壤深度的增加,灌木根系对土壤水分人渗的影响则开始减弱,而乔木较深的根系则 有助于土壤水分的进一步下渗, 因此, 未来需要对不同类型的园林植物进行优化配置, 确保绿地土壤的不同层 次均有根系分布, 从而最大化城市绿地的水分人渗性能 ${ }^{[1,19]}$ 。

绿地植物也会通过枯枝落叶和根系调亡向土壤归还有机质, 提高绿地土壤的水分人渗性能 ${ }^{[14,39-40]}$ 。研究 区灌草绿地的土壤容重小于乔草绿地,还可能与不同类型绿地的有机质归还能力存在差异有关。受树木冠层 构型差异的影响, 乔草绿地的调落物更易于清扫, 而灌草绿地受灌木丛状生长的影响, 其调落物常难以清扫而 得以保存。这与海珠湿地的调查结果较为一致,两处样地的灌草绿地调落物干重在 $92.38-95.34 \mathrm{~g} / \mathrm{m}^{2}$ 之间, 大于乔草绿地的调落物干重( $\left.22.33-64.73 \mathrm{~g} / \mathrm{m}^{2}\right)$ 。这有助于提高灌草绿地的土壤有机质含量, 促进水稳性 团聚体的形成, 改善其土壤结构。且有机质中的腐殖质表面积巨大, 富有亲水基团, 能够增强绿地土壤对水分 的吸持力 ${ }^{[23]}$, 同时也能为土壤微生物和土壤动物活动提供必要条件, 降低土壤容重, 增加非毛管孔隙的比例。 其次,调落物的存在也会提高土壤表面的粗糙度,滞缓雨洪的汇流时间,增加绿地土壤水分的累积人渗量 ${ }^{[16]}$ 。 最后, 根系在凋亡后, 不仅会提高土壤有机质含量, 还会进一步增加土壤大孔隙的比例 ${ }^{[38]}$ 。其中细根的分解 速率相对于粗根更快 ${ }^{[12,41]}$, 使得根系与土体之间形成更大的优先流通道, 进一步促进了绿地土壤的水分下 渗。本文的研究也发现, 同一样地灌草绿地的非毛管孔隙度总体大于乔草绿地, 可能与灌草的细根系主要集 中在土壤表层有关。不同类型绿地的有机质归还能力与其植被类型及人为干扰程度有关,未来需要研究不同 有机质归还能力下,城市绿地土壤水分人渗速率的变化特征。

\section{4 结论}

(1) 海珠国家湿地公园绿地土壤水分人渗性能处于中等至较高水平, 但受机械和人为压实影响, 其容重 偏大, 总孔隙率偏低。加上外来客土添加等的影响, 其土壤物理性黏粒含量较高, 且有部分人为侵人体混人, 进一步抑制了绿地土壤水分人渗。

(2) 植物生长可促进绿地土壤水分人渗, 以灌草对绿地土壤水分入渗性能的改善最为明显, 这主要与其 根系的分布近地表层有关。此外, 调落物和根系持续的归还土壤, 也在一定程度上促进了绿地土壤水分人渗。

(3) Philip、Horton 和 Kostiakov 模型均能够拟合不同植被类型的城市绿地土壤水分累积入渗量随时间的 变化特征,但以 Kostiakov 模型的拟合效果最佳。

后续绿地的建设过程中, 应注重乔灌草相结合, 并适当增加灌草比例, 减少人为侵入体及物理性黏粒含量 较高的客土如塘泥等混人。对已有绿地, 应设置专用廊道及固定休唕区, 减少绿地土壤的压实作用, 并注重凋 落物和根系的持续返还, 增加绿地土壤表层的团聚体含量, 兼顾城市绿地的旅游休闲和雨洪蓄积功能, 促进海 绵城市的高效建设。

\section{参考文献 (References) :}

[ 1 ] Xie C K, Cai S Z, Yu B Q, Yan L B, Liang A Z, Che S Q. The effects of tree root density on water infiltration in urban soil based on a Ground Penetrating Radar in Shanghai, China. Urban Forestry \& Urban Greening, 2020, 50: 126648.

[ 2 ] Grimm N B, Faeth S H, Golubiewski N E, Redman C L, Wu J G, Bai X M, Briggs J M. Global change and the ecology of cities. Science, 2008, 319(5864): 756-760.

[ 3 ] Ren X W, Hong N, Li L F, Kang J Y, Li J J. Effect of infiltration rate changes in urban soils on stormwater runoff process. Geoderma, 2020, 363 : 114158.

[ 4 ] 张彪, 谢高地, 薛康, 王金增, 肖玉, 张灿强. 北京城市绿地调蓄雨水径流功能及其价值评估. 生态学报, 2011, 31(13): 3839-3845.

[ 5 ] Donat M G, Lowry A L, Alexander L V, O' gorman P A, Maher N. More extreme precipitation in the world's dry and wet regions. Nature Climate Change, 2016, 6(5): 508-513.

[ 6 ] Rahman M A, Moser A, Anderson M, Zhang C, Rötzer T, Pauleit S. Comparing the infiltration potentials of soils beneath the canopies of two 
contrasting urban tree species. Urban Forestry \& Urban Greening, 2019, 38: 22-32.

[ 7 ] Farrugia S, Hudson M D, McCulloch L. An evaluation of flood control and urban cooling ecosystem services delivered by urban green infrastructure. International Journal of Biodiversity Science, Ecosystem Services \& Management, 2013, 9(2) : 136- 145.

[ 8 ] Yao L, Chen L D, Wei W, Sun R H. Potential reduction in urban runoff by green spaces in Beijing: A scenario analysis. Urban Forestry \& Urban Greening, 2015, 14(2): 300-308.

[9] 方政, 杜建会, 张思毅, 王晓瑜, 耿嘉灵, 颜瑞, 林志斌. 人为侵人体对城市绿地土壤水分人渗特征的影响. 水土保持学报, 2020 , 34 (4) : 124-130.

[10] Ebrahimian A, Sample-Lord K, Wadzuk B, Traver R. Temporal and spatial variation of infiltration in urban green infrastructure. Hydrological Processes, 2020, 34(4): 1016-1034.

[11] Zhang L Y, Oyake Y, Morimoto Y, Niwa H, Shibata S. Rainwater storage/infiltration function of rain gardens for management of urban storm runoff in Japan. Landscape and Ecological Engineering, 2019, 15(4): 421-435.

[12] Zhang X Y, Wang W. The decomposition of fine and coarse roots: their global patterns and controlling factors. Scientific Reports, 2015, 5 (1) : 9940 .

[13] 杨金玲, 张甘霖, 赵玉国, 赵文君, 何跃, 阮心玲. 城市土壤压实对土壤水分特征的影响一一南京市为例. 土壤学报, 2006, 43(1)： $33-38$.

[14] Phillips T H, Baker M E, Lautar K, Yesilonis I, Pavao-Zuckerman M A. The capacity of urban forest patches to infiltrate stormwater is influenced by soil physical properties and soil moisture. Journal of Environmental Management, 2019, 246: 11-18.

[15] 聂发辉, 李田, 姚海峰. 上海市城市绿地土壤特性及对雨洪削减效应的影响. 环境污染与防治, 2008, 30(2) : 49-52.

[16] 魏俊岭, 金友前, 郜红建, 常江, 徐薇. 合肥市绿地土壤水分人渗性能研究. 中国农学通报, 2012, 28(25)：302-307.

[17］戴子云. 北京城市绿地土壤水分人渗性能研究. 中国园林, 2019, 35( 6) : 105-108.

[18] 黄晖, 毕舒贻, 字肖萌, 廖耿强, 温暖玲, 茹正忠. 深圳城市绿地土壤人渗性能及影响因素研究. 中国农学通报, 2020, 36( 14): 74-79.

[19] 伍海兵, 方海兰, 彭红玲, 梁晶, 胡永红, 蔡云鹏, 郝冠军. 典型新建绿地上海辰山植物园的土壤物理性质分析. 水土保持学报, 2012, 26(6): 85-90.

[20］伍海兵, 方海兰. 绿地土壤人渗及其对城市生态安全的重要性. 生态学杂志, 2015, 34(3): 894-900

[21] 王思思, 王榕, 苏毅, 宫永伟. 北京城区绿地土壤渗透性能及其对降雨产流的影响分析. 环境工程. 2020, 38(4): 83-88.

[22]马建刚, 马建武, 陆梅. 昆明市公园绿地土壤人渗特征研究. 西南林业大学学报, 2016, 36(3): 111-115.

[23] 张晓凤, 张旭, 蒋晶, 李广贺. 北京奥林匹克森林公园典型下垫面人渗特性. 清华大学学报: 自然科学版, 2012, 52(2): 223-228.

[24] 伍海兵, 方海兰, 李爱平. 常用绿地土壤改良材料对土壤水分人渗的影响. 水土保持学报, 2016, 30(3): 317-323, 330-330.

[25] 朱永杰, 毕华兴, 霍云梅, 许华森. 北京地区下凹式绿地土壤渗透能力及蓄水对土壤物理性质的影响. 中国水土保持科学, 2015, 13(1)： 106- 110 .

[26] 孙万儒. 森林土壤分析方法. 北京: 中国标准出版社, 1999.

[27] Yang J L, Zhang G L. Water infiltration in urban soils and its effects on the quantity and quality of runoff. Journal of Soils and Sediments, 2011, 11 (5) : 751-761.

[28] 伍海兵, 方海兰, 彭红玲. 典型新建绿地上海辰山植物园土壤水库特征及其影响因子. 应用生态学报, 2016, 27( 5) : 1437-1444.

[29］管东生，何坤志，陈玉娟. 广州城市绿地土壤特征及其对树木生长的影响. 环境科学研究，1998，11(4): 51-54.

[30］伍海兵.上海中心城区典型绿地土壤物理性质特征研究. 土壤, 2018, 50( 1): 155-161.

[31 Wang P J, Zheng H F, Ren Z B, Zhang D, Zhai C, Mao Z X, Tang Z, He X Y. Effects of urbanization, soil property and vegetation configuration on soil infiltration of urban forest in Changchun, Northeast China. Chinese Geographical Science, 2018, 28(3): 482-494.

[32] Alizadehtazi B, Digiovanni K, Foti R, Morin T, Shetty N H, Montalto F A, Gurian P L. Comparison of observed infiltration rates of different permeable urban surfaces using a Cornell Sprinkle Infiltrometer. Journal of Hydrologic Engineering, 2016, 21( 7) : 06016003.

[33] 杨倩, 刘目兴, 王苗苗, 张海林, 朱强, 易军. 武汉市典型绿地植被类型对表层土壤人渗和持水性能的影响. 长江流域资源与环境, $2019,28(6)$ : 1324-1333.

[34] 李华, 杨世伦, Ysebaert T, 王元叶，李鹏，张文祥. 长江口潮间带淤泥质沉积物粒径空间分异机制. 中国环境科学，2008，28(2)： 178- 182 .

[35] 李卓, 吴普特, 冯浩, 赵西宁, 黄俊. 不同粘粒含量土壤水分人渗能力模拟试验研究. 干旱地区农业研究, 2009, 27(3): 71-77.

[36] Yu B Q, Xie C K, Cai S Z, Chen Y, Lv Y P, Mo Z L, Liu T L, Yang Z W. Effects of tree root density on soil total porosity and non-capillary porosity using a Ground-Penetrating Tree Radar Unit in Shanghai, China. Sustainability, 2018, 10(12): 4640.

[37] Chandler K R, Chappell N A. Influence of individual oak ( Quercus robur) trees on saturated hydraulic conductivity. Forest Ecology and Management, 2008, 256(5): 1222-1229.

[38] Lange B, Lüescher P, Germann P F. Significance of tree roots for preferential infiltration in stagnic soils. Hydrology and Earth System Sciences, $2009,13(10): 1809-1821$.

[39] 刘目兴, 聂艳, 于婧. 不同初始含水率下粘质土壤的人渗过程. 生态学报, 2012, 32(3): 871-878.

[40] Zhang D S, Dai Y, Wang L L, Chen L. Influence of living and dead roots of Gansu Poplar on water infiltration and distribution in soil. Applied Sciences, 2020, 10(10): 3593 .

[41] Huang C J, Wu C S, Gong H D, You G Y, Lu H Q. Decomposition of roots of different diameters in response to different drought periods in a subtropical evergreen broad-leaf forest in Ailao Mountain. Global Ecology and Conservation, 2020, 24 : e01236. 